\title{
Validation of An Instrument to Know the Use of Smart Devices in Air Conditioners and Their Improvement in Energy Efficiency: Case Study in Ecuador
}

\author{
https://doi.org/10.3991/ijoe.v17i04.21117 \\ Jorge Anchundia-Santana \\ Universidad Laica Eloy Alfaro de Manabí, Manta, Ecuador \\ Julieta Evangelina Sánchez-Cano \\ Universidad Juárez del Estado de Durango, Dgo, México \\ Washington Xavier García-Quilachamin ${ }^{(}{ }^{\bowtie}$, Evelyn Santana Mantuano \\ Universidad Laica Eloy Alfaro de Manabí, Manta, Ecuador \\ profegarcia501@gmail.com
}

\begin{abstract}
The constant growth of the world's population has generated various changes in the use of the diversity of the resources provided to us by the planet. Considering that by properly managing energy in air conditioning systems correctly, it collaborates in the fight against climate change, reducing the excessive use of fossil fuels and, therefore, the emission of $\mathrm{CO} 2$ and other greenhouse gases, creating an environment of comfort in industrial sectors, businesses, companies, homes, among others. The objective of this research is to validate the instrument considering the information obtained about smart devices applied in air conditioning systems and their improvement in energy efficiency. The methodology applied consisted of a field study conducted through an online survey that was directed at 226 students and professionals from three provinces of the Republic of Ecuador. To validate the data obtained in the instrument, the exploratory factor analysis was performed also of the principal components in the last phase it was obtained in factor transformation matrix (0.986), which demonstrates the validity of the study. To apply the KMO test and Bartlett's sphericity, the following ranges $(\geq 0.6)$ y $(<0.05)$ were considered respectively.
\end{abstract}

Keywords - Factor analysis, variable correlation, smart devices, air conditioners, energy efficiency

\section{Introduction}

The constant increase in the population at a global level has generated a high demand in the use of the diversity of resources that the planet provides. Therefore, laws have now been created that seek to combat the excessive use of non-renewable resources, which are ceasing to exist in abundance. As the population increases, and as electricity has become a global necessity, governments find it necessary to implement strategies 
that contribute to the efficient use of electrical energy, which is why laws arise that promote efficient energy management, in order to reduce payroll cost, extend the useful life of their equipment and optimize processes [1]. Considering that managing energy correctly also helps in the fight against climate change, reducing the misuse of fossil fuels and therefore the emission of $\mathrm{CO} 2$ and other greenhouse gases, as stated [2], [3].

The authors [4], [5], [6] indicate that through efficient technologies, environmental damage and costs related to energy use can be reduced. According to [7], the terms energy efficiency and energy saving, have a common purpose, to reduce the excessive consumption of electrical energy, saving being the use of adequate measures to reduce such consumption, using energy management methods, among those that stand out, the use and application of smart systems and devices that are connected to the equipment, seek to make them efficient, use less energy, and therefore consume fewer resources, as stated [8].

Currently, intelligent systems are present in a greater number globally, considering artificial intelligence and the IoT as the emerging technologies of the future, based on the development and application of techniques that allow detecting people, running in various scenarios, either surveillance, identification, security, automation, energy efficiency, among others.

Based on the study carried out, it is considered a challenge to manage the proper use of air conditioners, which by the year 2050 have been stipulated that their presence in homes and buildings will exceed 1600 million units. As stated [9], [10], this will bring about a considerable increase in the demand for electrical energy. Therefore, based on these problems, one of the main challenges of modern society is to go further in terms of the use of technologies that are sustainable, intelligent, efficient and that, when synchronized, provide comfort in the lifestyle of its users, at a low cost in its consumption.

According to the study carried out by the authors [11], our research is based on a systematic review that mentions technologies with smart devices applied to lighting systems (various types of sensors), this allowed us to determine our study on the use of smart devices applied to air conditioners for an improvement in energy efficiency.

The objective of this study is to validate the instrument considering the information obtained about smart devices applied in air conditioning systems and their improvement in energy efficiency. This research was developed through a field study conducted through an online survey that was directed to 226 students and professionals from three provinces of the Republic of Ecuador.

This document is divided as follows, section 2 comprises the applied methodology, which describes the way in which this study has been developed, as well as the participants involved, applied instrument and statistical analysis. Section 3 shows the results obtained through the factor analysis, which will be shown in tables that represent the relevant data of the analysis, considering the application of the KMO test and Bartlett's sphericity, and finally describes the conclusions reached in this research. 


\section{Methodology}

\subsection{Participants}

This research is based on a field study carried out virtually in three provinces of Ecuador, for which a total sample of 226 surveys carried out and with the information obtained in relation to the application of intelligent systems in air conditioners was considered, this study makes it possible to determine the level of knowledge of people about the use of these air conditioning equipment.

The field study was aimed at students and professionals from various areas of knowledge, considering three provinces (Manabí, Guayas, and Esmeraldas) for their climate and temperature, mainly because the thermal sensation is moderately high and the results of this research allow to determine the level of knowledge about energy efficiency in air conditioners $(\mathrm{A} / \mathrm{C})$ and the way they are used.

\subsection{Instrument}

The instrument consists of 14 items divided into two sections, the first of 4 items where it refers to the personal data, training and academic activity of the respondent. The second consist of 10 items associated with energy efficiency in air conditioners and divided into two subsections: level of knowledge and application.

The responses were stored anonymously in a database created by default in the forma used for this study. The creation of files with the type of response required for the development of this research was based on the Likert scale. Based on the information obtained and filtered in Microsoft Excel, the data was entered into de SPSS Statistical Software to proceed with the exploratory factor analysis.

\subsection{Statistical analysis}

The analysis of the information Through the statistical software SPSS (Statistical Package for the Social Science), is carried out in order to validate this study, considering that among its tools it has the factor analysis (AF), which is a statistical model that is used to represent the relationships between variables of a set, that is, it shows the existence of variables that measure the same phenomenon when they are related. According to the authors [12], these relationships are explained by a series of unobserved (latent) variables, which are called factors, where the number of factors is considerably less than the number of variables. Therefore, among the techniques that are within the factor analysis, is the exploratory factor analysis (EFA), which allows us to observe the extent to which the variables that make up the set adequately represent the end of the study, as indicated by the author [13].

According to [14], when applying the exploratory approach (EFA) in this investigation, the theoretical data will be aligned with the empirical ones, which result from the reduction of the variables established to small factors or dimensions. Where 
each of the factors groups the items that correlate with each other, and at the same time are independent of the remaining factors.

The author [15] considers that to determine with greater reliability the validity of the construct of the questionnaire it is necessary to carry out other complementary factor analysis test. This is why Principal Component Analysis (PCA) is applied, which meets the objective of reducing the dimensionality of data set, losing the least amount of information possible. According to the authors [16], they state that PCA is a technique used to find the causes of variability in a set of data and order them by importance, in order to know the interrelationships between the variables analyzed.

This research focuses on analyzing the information obtained in relation to smart devices applied in air conditioners with energy efficiency criteria, which is why it is expressed through a certain linear combination of the variables contained in the questionnaire. Considering [17], the dimensions of the established items allowed obtaining a correlation coefficient $>0.6$, which was considered as a feasible value to start this study and develop the exploratory factor analysis based on the data obtained in the survey that was applied in three provinces of Ecuador.

\subsection{Validation of the instrument}

To validate the instrument and the information obtained through the items proposed in the questionnaire, the factor analysis is carried out in the SPSS software, starting with the analysis of the principal components, which are used to order and quantify the categorical variables, and gradually reduce the size of the data, putting from largest to smallest, that is, the variables are ordered according to amount of information they have, so that the former contain a lot of information and the latter less information, as stated by the authors [18], [19] allowing validation and reliability of already reduced data.

Based on the principal component analysis, the Kaiser-Meyer-Olkin (KMO) and Bartlett's sphericity test were performed. Considering the authors [20], [21] y [22], who state that the KMO test is the one that compares the values of the observed coefficients, this statistical procedure takes the value between 0 and 1 , and, the closer it is to 1 , continuity of the technique will be more appropriate, in this research the values greater than 0.6 were considered.

\subsection{Factor analysis}

The factor analysis was carried out on the 10 items that comprise the second section of the questionnaire, which were applied through the instrument in three Province of Ecuador, to reach a definitive analysis and establish the reagents that are related to each other, focused on the use of smart devices applied in air conditioners to improve energy efficiency.

The statistical process was developed in three phases: in the first phase, 1 reagent was extracted, which had a correlation coefficient lower than 0.6 ; in the second phase, 1 reagent was extracted that did not comply with the established coefficient value; In 
the third and last phase, 2 reagents that were not within the established range were eliminated.

Of the 10 reagents considered in the analysis, it was obtained that 6 of them are correlated with each other, because their correlation coefficient value is $>0.6$, indicating that the factor analysis is effective and has validity, as stated by the authors [23].

\section{$3 \quad$ Results and Analysis}

The results shown in this research show that there is a relationship between the level of knowledge and application, in view of the fact that there is a difference in the 6 items obtained as a result, of which 5 of them belong to the section on the level of knowledge, the majority being the correlation between variables that mention the use of smart devices focused on improving the energy efficiency.

In relation to the knowledge section, it was obtained that most of the responses are established based on the two lowest data $(1,2)$, which correspond to the criteria, No and Very little, within the Likert scale.

This analysis allowed obtaining as a result that more than $60 \%$ of the sample do not have knowledge about technological advances, consumption policies, among other ways of managing energy correctly. On the other hand, in the application section, it was found that between 40 and $50 \%$ of the sample responded that they forget to turn off the air when not using them, that they do not perceive comfort and that they do not consider the consumption generated by this equipment when using them.

These results allowed us to determine two options for the evaluation of this information, the first and clearly visible is due to the fact that a percentage greater than $50 \%$ of the sample do not know about the subject, use the air without any established schedule or remain on for long periods of time, having or not people in the room; the second option would encompass electrical-electronic technological advances aimed at collaborating with $\mathrm{A} / \mathrm{C}$ energy management.

\subsection{Results and analysis of the first phase}

In this first phase, the 10 reagents that are part of the second section of the questionnaire are entered into SPSS, seeking to reduce the dimensions of the variables. To obtain the expected result, the Bartlett's sphericity test and the KMO test are applied in the software, considering within the range 0.6 as the minimum correlation value between the reagents for KMO, and the critical level (Sig.) must be $<0.05$ to reject the null hypothesis and allow the EFA to be performed. 
Table 1. Results of KMO and Bartlett's test

\begin{tabular}{|l|l|c|}
\hline \multicolumn{2}{|c|}{ Kaiser-Meyer-Olkin measure of sampling adequacy. } &, 806 \\
\hline \multirow{3}{*}{ Bartlett's sphericity test } & Approximate chi- square & 803,093 \\
\cline { 2 - 3 } & gl & 45 \\
\cline { 2 - 3 } & Sig. &, 000 \\
\hline
\end{tabular}

Considering the previously detailed parameters, the analysis was carried out, where it was obtained that this phase is within the study range, with (0.806) for KMO and in Bartlett's sphericity the critical level (.000), which allows us to continue with the next stage of the analysis by showing that there is a correlation between variables. See table 1.

The table 2 shows the matrix of rotated components, considering that the correlation value between variables must be $\geq 0.6$, for this reason correlations lower than that range must be discarded and then a second stage of factor analysis should be carried out. At this stage, a reagent was found that does not correlate with the others, because its value (0.562) is lower than the established one. In the table 2 the text related to the reagent that is going to be extracted to carry out the second stage is highlighted in color.

Table 2. Rotated Component Matrix

\begin{tabular}{|l|c|c|c|}
\hline & \multicolumn{3}{|c|}{ Component } \\
\cline { 2 - 4 } & $\mathbf{1}$ & $\mathbf{2}$ & $\mathbf{3}$ \\
\hline Do you know about energy efficiency in air conditioners? &, 839 &, 071 &, 079 \\
\hline $\begin{array}{l}\text { Do you have knowledge about the technological advances related to energy } \\
\text { efficiency applied to air conditioning? }\end{array}$ &, 876 &,- 017 &, 023 \\
\hline Do you have knowledge about ISO 50001 for energy management? &, 767 &, 075 &,- 098 \\
\hline $\begin{array}{l}\text { Do you have knowledge about the benefits that the application of methods } \\
\text { to generate energy efficiency in air conditioning would bring? }\end{array}$ &, 851 &,- 025 &, 126 \\
\hline $\begin{array}{l}\text { Do you know if some type of technological management is applied for en- } \\
\text { ergy efficiency in air conditioning systems in homes and workplaces? }\end{array}$ &, 817 &, 115 &, 046 \\
\hline How regularly do you use air conditioners? &, 072 &, 855 &, 194 \\
\hline Do you turn off air conditioners when they are not in use? &, 124 &, 212 &, 745 \\
\hline Do you use air conditioners during extend hours? &, 047 &, 881 &, 072 \\
\hline $\begin{array}{l}\text { When entering a place where they use air conditioners, do you perceive } \\
\text { an environment of comfort? }\end{array}$ &,- 062 &, 036 &, 562 \\
\hline $\begin{array}{l}\text { Do you consider the economic cost generated by the air conditioners in your } \\
\text { workplace, study or home? }\end{array}$ &, 076 &, 049 &, 793 \\
\hline
\end{tabular}

Completing the first stage of the analysis, Table 3 shows the transformation matrix of the components, which describes that there is a relationship between components.

Table 3. Component Transformation Matrix

\begin{tabular}{|c|c|c|c|}
\hline Component & $\mathbf{1}$ & $\mathbf{2}$ & $\mathbf{3}$ \\
\hline 1 &, 966 &, 186 &, 181 \\
\hline 2 &,- 259 &, 682 &, 684 \\
\hline 3 &, 004 &,- 707 &, 707 \\
\hline
\end{tabular}




\subsection{Results and analysis of the second phase}

In this second stage, the reagent extracted in the first stage is not considered, so the analysis is carried out with 9 variables applying the same analysis as in the first stage, in contrast, instead of analyzing the components, maximum likelihood analysis is applied to the fit the values that are most closely related to each other.

In table 4 it is observed that the correlation between variables is repeated, obtaining a value of (0.812) for KMO and the critical level (Sig.) It remains the same in relation to the first phase (.000). With these values obtained, it is determined that there is a correlation, likewise, its values are higher than in the first stage, which indicates that, while the KMO value is closer to 1 , the analysis is feasible.

Table 4. Second Results of KMO and Bartlett's test

\begin{tabular}{|l|l|c|}
\hline \multicolumn{2}{|c|}{ Kaiser-Meyer-Olkin measure of sampling adequacy. } &, 812 \\
\hline \multirow{3}{*}{ Bartlett's sphericity test } & Approximate chi- square & 781,901 \\
\cline { 2 - 3 } & Gl & 36 \\
\cline { 2 - 3 } & Sig. &, 000 \\
\hline
\end{tabular}

In the first phase, a reagent that was not within the specified range was extracted, and in this second stage one more reagent is discarded, whose value is $>0.6$, therefore, it must be eliminated in the new stage to be performed. The Table 5 shows the text related to the reagent that will be eliminated due to its lower determined value $(0.462)$ in highlighted black.

Table 5. Rotated component matrix

\begin{tabular}{|l|c|c|c|}
\hline & \multicolumn{3}{|c|}{ Factor } \\
\cline { 2 - 4 } & $\mathbf{1}$ & $\mathbf{2}$ & \multicolumn{1}{|c|}{$\mathbf{3}$} \\
\hline Do you know about energy efficiency in air conditioners? &, 805 &, 064 &, 098 \\
\hline $\begin{array}{l}\text { Do you have knowledge about the technological advances related to energy } \\
\text { efficiency applied to air conditioning? }\end{array}$ &, 867 &, 006 &, 009 \\
\hline Do you have knowledge about ISO 50001 for energy management? &, 671 &, 064 &, 023 \\
\hline $\begin{array}{l}\text { Do you have knowledge about the benefits that the application of methods to } \\
\text { generate energy efficiency in air conditioning would bring? }\end{array}$ &, 803 &,- 009 &, 146 \\
\hline $\begin{array}{l}\text { Do you know if some type of technological management is applied for energy } \\
\text { efficiency in air conditioning systems in homes and workplaces? }\end{array}$ &, 758 &, 113 &, 079 \\
\hline How regularly do you use air conditioners? &, 071 &, 614 &, 264 \\
\hline Do you turn off air conditioners when they are not in use? &, 074 &, 131 &, 906 \\
\hline Do you use air conditioners during extend hours? &, 046 &, 878 &, 069 \\
\hline $\begin{array}{l}\text { Do you consider the economic cost generated by the air conditioners in } \\
\text { your workplace, study or home? }\end{array}$ &, 066 &, 119 &, 462 \\
\hline
\end{tabular}

The transformation matrix of the factors shown in Table 6, describes that there is still a correlation between variables. In this case, the matrix is still maintained in three factors that are closely related to each other. 
Table 6. Table 6 Factor transformation matrix

\begin{tabular}{|c|c|c|c|}
\hline Factor & $\mathbf{1}$ & $\mathbf{2}$ & $\mathbf{3}$ \\
\hline 1 &, 904 &, 221 &, 366 \\
\hline 2 &,- 428 &, 476 &, 768 \\
\hline 3 &, 005 &, 851 &,- 525 \\
\hline
\end{tabular}

\subsection{Results and analysis of the third phase}

The 10 reagents analyzed in the two stages described, 2 of them were eliminated, which were not in the study range, therefore 8 variables that have a close relationship between them are considered. After the two phases, the third and last stage of analysis of this research is carried out, where two reagents are rejected that, due to the result obtained, do not fall within the study range, leaving a total of 6 variables closely related to each other, with a correlation coefficient $>0.6$.

In this stage, figure 1 is obtained, related to the sedimentation graph, to determine the factors to retain in this third phase.

It is considered that in phase one and two, 3 factors were retained, and in this third phase, 2 rotated factors are retained, which allows us to validate and determine in this research, that in order to perform a correlation analysis there must be at least two factors which relate.

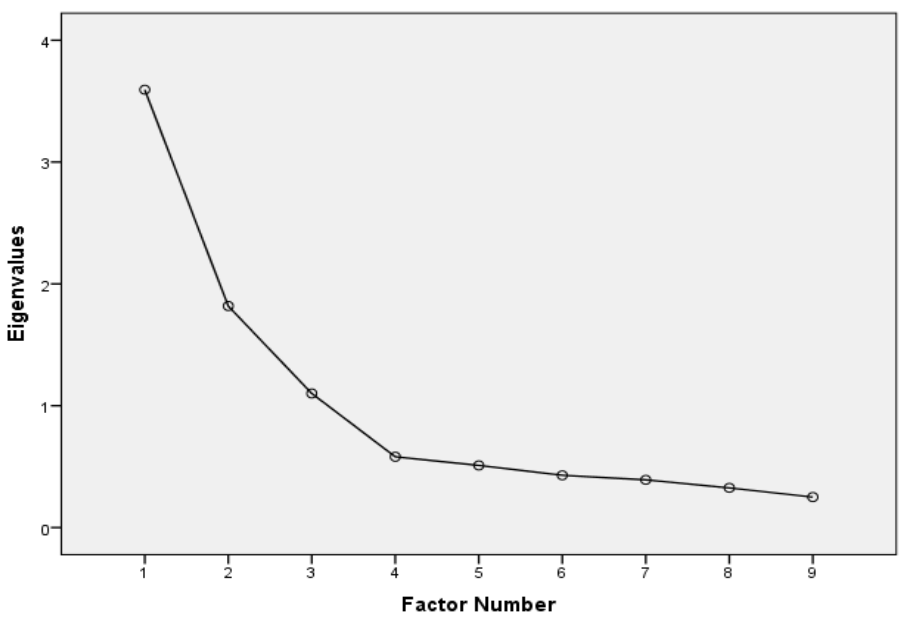

Fig. 1. Sedimentation graph

The Table 7 shows that the correlation between variables is much higher in relation to the previous phases. Obtaining a value of $(0.822)$ for KMO and the critical level (Sig.) remains at its satisfactory value (.000). With this data obtained, it is determined that there is a correlation between variables, and their values are closer to 1, showing that the research has been on track from the first stage. 
Table 7. Third KMO result and Bartlett's test

\begin{tabular}{|l|l|c|}
\hline \multicolumn{2}{|c|}{ Kaiser-Meyer-Olkin measure of sampling adequacy } &, 822 \\
\hline \multirow{3}{*}{ Bartlett's sphericity test } & Approximate chi- square & 733,394 \\
\cline { 2 - 3 } & gl & 28 \\
\cline { 2 - 3 } & Sig. &, 000 \\
\hline
\end{tabular}

In phase one and phase two, 2 reagents were extracted, as observed in Tables 2 and 5 . Thus, in this third phase, 2 more reagents are discarded, completing a total of 4 reagents extracted during the applied statistical analysis.

The table 8 shows that, there are 2 reagents that do not correlate with the others, but the matrix of transformed factors already has its minimum factor value (2), so this study is concluded with the process of analysis of the information collected. Considering that a total of 6variables fulfill the purpose of the analysis, and the remaining 4 were far from the subject of study.

Table 8. Rotated factor matrix

\begin{tabular}{|l|c|c|}
\hline \multirow{2}{*}{} & \multicolumn{2}{|c|}{ Factor } \\
\cline { 2 - 3 } Do you know about energy efficiency in air conditioners? & $\mathbf{1}$ & $\mathbf{2}$ \\
\hline $\begin{array}{l}\text { Do you have knowledge about the technological advances related to energy effi- } \\
\text { ciency applied to air conditioning? }\end{array}$ &, 803 &, 146 \\
\hline Do you have knowledge about ISO 50001 for energy management? &, 052 \\
\hline $\begin{array}{l}\text { Do you have knowledge about the benefits that the application of methods to gen- } \\
\text { erate energy efficiency in air conditioning would bring? }\end{array}$ &, 808 &, 072 \\
\hline $\begin{array}{l}\text { Do you know if some type of technological management is applied for energy ef- } \\
\text { ficiency in air conditioning systems in homes and workplaces? }\end{array}$ &, 756 &, 136 \\
\hline How regularly do you use air conditioners? &, 014 &, 969 \\
\hline Do you turn off air conditioners when they are not in use? &, 122 &, 333 \\
\hline Do you use air conditioners during extend hours? &, 029 &, 578 \\
\hline
\end{tabular}

The table 9 shows the two factors reached in this research, which are within the range established for the study. In this instance, a comparison is made between the factor with the most variability obtained in phase one (0.966), and the factor with the most variability in the third phase, that in this case are the two factors, because they have the same value correlation (0.966), demonstrating that the analysis developed in this research is related to the correlation between variables, because the established correlation value (0.6) does not lower, on the contrary, it has remained well above the range.

Table 9. Factor transformation matrix

\begin{tabular}{|c|c|c|}
\hline Factor & $\mathbf{1}$ & $\mathbf{2}$ \\
\hline 1 &, 170 &, 986 \\
\hline 2 &, 986 &,- 170 \\
\hline
\end{tabular}




\section{Conclusion}

In the organization of the data collected in the field study, it was observed that those involved in the research do not possess the level of knowledge about energy efficiency in regards to air conditioners. Likewise, in the use of $\mathrm{A} / \mathrm{C}$, the participants responded in a divided way, showing that they do not use the $\mathrm{A} / \mathrm{C}$ correctly, either due to lack of culture, or due to lack of knowledge about the excessive consumption of electrical energy generated by the $\mathrm{A} / \mathrm{C}$ equipment. This infers in homes, which have an air conditioning system where techniques and /or methods are not applied to generate energy efficiency, therefore, the misuse of these electrical-electronic devices is evidenced in the electrical worksheet, where it is shown that a considerable percentage of Mw/h consumed belong only to air conditioning equipment.

The exploratory factor analysis (EFA) applied to the items described in the questionnaire was carried out in order to obtain a correlation between the variables raised, in order to validate the research topic. Based on what has been described, the EFA was carried out, including the techniques of the KMO test and Bartlett's sphericity, considering the correlation range $\geq 0.6$ between the reagents analyzed. Proceeding with the first phase of the analysis, it was found that there was indeed a correlation between variables, since all were different from zero (0.806). In the second phase there was a correlation again, with the difference that the range was greater than that of the first stage $(0.812)$, result that continued to provide validity to the analysis process.

In the third and last phase, a correlation between variables was maintained (0.822), which turned out to be greater than the two previous stages. At this point in the research, it was evident that there was a close correlation between the reagents that were left, following the analysis of each phase, and to demonstrate the validity of the construct, the last result obtained from the factor transformation matrix (0.986) was considered, which shows that the analysis was on track during at the previous phases.

With regard to the results obtained in the Bartlett sphericity test, it was evidenced that the critical level (Sig.) was a very satisfactory value (.000) during the development of the three phases, since the critical level (Sig.) must be $<0.05$ to reject the null hypothesis and allow the EFA to be performed.

It is concluded that it is important to raise awareness, about the need to use smart devices applied to air conditioning equipment, which would positively contribute to improving energy efficiency in this area, as well as having a culture oriented towards good use of these teams would also collaborate to use them correctly and efficiently, which would reduce excessive consumption in the electricity tables.

\section{$4 \quad$ References}

[1] Aprende Con Energía, "Energía y Sociedad," 2015.

[2] D. Bravo Hidalgo and Y. Martínez Perez, "Eficiencia energética, competitividad empresarial y economía verde.," Rev. Publicando, vol. 3, no. 9, pp. 447-466, 2016.

[3] M. Poveda, "Eficiencia Energética: Recurso no aprovechado," Lat. Am. Energy Organ., p. 25, 2007. 
[4] T. D. Gerarden, R. G. Newell, and R. N. Stavins, "Assessing the Energy-Efficiency Gap," Natl. Bur. Econ. Res., vol. 53, no. 9, pp. 1689-1699, 2015.https://doi.org/10.3386/w20904

[5] A. Carretero Peña and J. M. García Sanchez, "Gestión de la eficiencia energética: cálculo del consumo, indicadores y mejora.," AENORediciones, pp. 1-28, 2012.

[6] S. A. Carrillo Fernandez and R. A. Velandia Velandia, "Propuesta para la implementación de una alternatiav que permita mejorar la eficiencia energética en el edificio Rafel Arboleda de la Pontifica Universidad Javeriana, Bogotá,” Pontifica Universidad Javeriana, Bogotá, 2016.https://doi.org/10.31910/rudca.v14.n1.2011.765

[7] A. Ruiz and E. Hall Mitre, "Desarrollo de un sistema de gestión de eficiencia y ahorro energético para las instituciones del sector público," vol. 3, 2017.https://doi.org/10.18235/ $\underline{0002362}$

[8] C. Cegelski et al., "Capacitación en el uso eficiente de la energía eléctrica: ahorro y medio ambiente," Tekohá, vol. 1, no. August 2018, pp. 43-49, 2017. Result score too low

[9] M. Ayuso Rejas, "Contaminación: El peligro oculto del aire acondicionado," El Confidencial, 2016.

[10] I. Gómez, "La demanda de aire acondicionado disparará el consumo eléctrico en el mundo," GeotermiaOnline, May-2018. [Online]. Available: https://geotermiaonline.com/2018/ 05/aire-acondicionado-refrigeracion/. [Accessed: 18-Jul-2020]. https://doi.org/10.3989/ic. 1964.v16.i159.4568

[11] García.W, Sanchéz.J, Santana.E, and P.Luzmila., "Validation of the Algorithm in the Detection of the Image of a Person Based on the Control of a Lighting Device," iJOE, vol. 16, no. $9,2020$.

[12] P. López-Roldán and S. Fachelli, "Metodología De La Investigación Social Cuantitativa," in Universidad Autónoma de Barcelona, Barcelona, España, 2016, p. 140.

[13] I. Mavrou, “Análisis factorial exploratorio: Cuestiones conceptuales y metodológicas," Revista Nebrija de Lingüística Aplicada, no. 19, p. 10, 2015.

[14] A. Hefetz and G. Liberman, "The factor analysis procedure for exploration: a short guide with examples / El análisis factorial exploratorio: una guía breve con ejemplos," Taylor Fr., vol. 29, no. 3, pp. 526-562, 2017. https://doi.org/10.1080/11356405.2017.1365425

[15] J. Echeverría, “Apropiación social de las tecnologías de la información y la comunicación," Qurriculim, vol. 4, pp. 91-115, 2002.

[16] H. Á. Pérez, S. G. Ibañez, and J. L. Rosas-acevedo, “Análisis de Componentes Principales, como herramienta para interrelaciones entre variables fisicoquímicas y biológicas en un ecosistema léntico de Guerrero , México,” 2015.

[17] W. Garcia, "Curso De Experto: 'Metodología De La Investigación," Curso Expert. "Metodol. LA Investig.," vol. 1, p. 23, 2017.

[18] M. Lezama, M. Cruz, and B. Pico, "Las competencias de liderazgo en los mandos medios de la comisión federal de electricidad: análisis de sus principales componentes," in Red Internacional de Investigadores en Competitividad, 2016, no. 9, pp. 198217.https://doi.org/10.21676/16574923.2779

[19] F. Enrique, R. Sánchez, and A. Eduardo, "Estudio Cuantitativo Del Estado Actual Del Proceso De Enseñanza- Aprendizaje De Una Disciplina Mediante Análisis De Componentes Principales Para Datos Categóricos," Research Gate, vol. 40, no. September, 2019.https://doi.org/10.36260/rbr.v8i12.871

[20] T. Romero Díaz and A. Martínez Gimeno, "Elaboration and validation of an evaluation questionnaire to teacher performance through Exploratory Factor Analysis," Rev. Científica FAREM-Estelí. Medio Ambient. Tecnol. y Desarro. Hum., vol. 6, no. 22, pp. 18-30, 2017.https://doi.org/10.5377/farem.v0i22.4514 
[21] C. Santos and A. León, "La medición De Los Resultados Sociales En El Sector Bananero; Un Estudio De Corte Transversal En La Provincia De Los Ríos, República Del Ecuador,” Universidad, Cienc. y Tecnol., vol. 23, pp. 107-118, 2019 .https://doi.org/10.35537 /10915/45729

[22] W. Garcia-Quilachamin, E. Santana, and J. Pro-Concepción, L. Salazar-Richard, "Validation of an Instrument Applied in Public Institutions of Ecuador to Know the Use of Intelligent Systems," iJOE, vol. 15, pp. 42-56, 2019.https://doi.org/10.3991/ijoe.v15i12.11007

[23] R. Serrano Rodríguez, M. I. Amor Almedina, Á. Guzman Cedeño, and J. Guerrero-Casado, "Validation of an Instrument to Evaluate the Development of University Teaching Competences in Ecuador," J. Hispanic High. Educ., 2018.https://doi.org/10.1177/15381927 $\underline{18765076}$

\section{Authors}

Jorge Anchundia-Santana is from Universidad Laica Eloy Alfaro de Manabí, Manta, Ecuador. Email: jorge.anchundia19@hotmail.com

Julieta Evangelina Sánchez-Cano is from Universidad Juárez del Estado de Durango, Dgo, México. Email: mailto:julieta.san2009@ujed.mx

Washington Xavier García-Quilachamin is from Universidad Laica Eloy Alfaro de Manabí, Manta, Ecuador. Email: profegarcia501@gmail.com

Evelyn Santana Mantuano is from Universidad Laica Eloy Alfaro de Manabí, Manta, Ecuador. Email: mailto:evelyn-271@ hotmail.com

Article submitted 2021-01-13. Resubmitted 2021-02-11. Final acceptance 2021-02-14. Final version published as submitted by the authors. 